\title{
Os Agentes Sociais da Rede de Proteção e Atendimento no Enfrentamento da Exploração Sexual Comercial
}

\author{
Social Agents from Protection Networks in Fighting Commercial \\ Sexual Exploitation
}

\author{
Maria de Fátima Pereira Alberto*, a , Ana Cristina Serafim da Silva ${ }^{b}$, \\ Vanessa Cavalcante Gomes ${ }^{a}$, Roberta Valesca Mota Santana ${ }^{a} \&$ Àdria Melo Soares ${ }^{a}$ \\ ${ }^{a}$ Universidade Federal da Paraíba, João Pessoa, Brasil \& ${ }^{b}$ Universidade Federal do Tocantins, Palmas, Brasil
}

\begin{abstract}
Resumo
Neste artigo, apresentam-se dados de pesquisa sobre a percepção dos Agentes Sociais que atuam no enfrentamento da exploração sexual comercial de crianças e adolescentes. As entidades caracterizam-se por Organizações Governamentais, Organizações Não-Governamentais, Sistema de Justiça e Instâncias de Direitos. Compõem uma Rede de 15 instituições e foram entrevistados 31 Agentes Sociais de 12 delas. Utilizou-se um questionário composto de questões abertas e fechadas sobre: Conhecimento do Sistema de Proteção; Percepção da ESCCA; Formas de Enfrentamento da ESCCA; Procedimentos e Medidas em casos de suspeitas, identificações, denúncias e notificações. A maioria dos Agentes Sociais tem conhecimento do papel da instituição, embora alguns desconheçam parte da Legislação e as formas de se efetivar na prática o papel daquelas e a articulação interinstitucional.

Palavras-chave: Exploração sexual, atores sociais, crianças e adolescentes, violência.
\end{abstract}

\begin{abstract}
This article shows the data collected in a research regarding the perception of Social Agents who act in fighting children and adolescents' commercial sexual exploitation. The networking is composed by Governmental Organizations, Non-governmental Organizations, Justice System and Human Rights entities. They compose a network of 15 institutions, and 31 Social Agents who belonged to 12 of them were interviewed. It was used a questionnaire composed by open and closed questions about protection systems knowledge; perception of children and adolescents' commercial sexual exploitation; forms of fighting children and adolescents' commercial sexual exploitation; procedures and actions in case of suspicion, identification, denunciation and notification. Most of the Social Agents who make part of the network know the role of the institution where they work, although some of them do not know part of the Legislation which deals with this problematic and they also do not know the forms to effectuate in practice the purpose of the Legislation and its inter-institutional articulation.

Keywords: Sexual exploitation, social agents, children and adolescents, violence.
\end{abstract}

Esse artigo versa sobre os dados de pesquisa cujos objetivos eram caracterizar as entidades que participam do enfrentamento da violência sexual infanto-juvenil, identificar a percepção dos agentes sociais que atuam nessas entidades sobre o enfrentamento da exploração sexual comercial de crianças e adolescentes. Por agentes sociais, compreendem-se os funcionários e voluntários que atuam nas entidades responsáveis pela Proteção, Defesa e Garantia dos Direitos de crianças e adolescentes e que compõem as redes de serviços e atendimentos responsá-

\footnotetext{
${ }^{*}$ Endereço para correspondência: Universidade Federal da Paraíba, Centro de Ciências Humanas Letras e Artes, Departamento de Psicologia, Cidade Universitária, Campus I, Castelo Branco, João Pessoa, PB, Brasil 58000-000. E-mail: jfalberto@uol.com.br, aninhacris000@hotmail.com, vanessinhacg@bol.com.br, baianinha_pb@hotmail.com e adrimel123@yahoo.com.br
}

veis pelo enfrentamento da violência sexual infanto-juvenil em cada município brasileiro.

A categoria violência sexual é um elemento conceitual, e, portanto, explicativo, de todas as situações em que crianças e adolescentes são vitimizadas e exploradas sexualmente. A violência sexual contra crianças e adolescentes evidencia-se sob várias formas e apresenta maneiras diferenciadas de expressão, tais como: estupro, incesto, atentado violento ao pudor, abuso sexual e exploração sexual comercial.

O abuso sexual é caracterizado por uma assimetria determinante para a condição de abuso de uma pessoa sobre outra. Trata-se da concepção de que o agressor possui desenvolvimento psíquico ou físico maior que o de sua vitimada, o que presume detenção de poder sobre a criança ou o adolescente. $\mathrm{O}$ intuito do abusador é buscar o prazer sexual com crianças ou com adolescentes e para 
isso torna comum a presença de outros artifícios de manifestação desse domínio, como jogo de sedução, ameaça ou chantagem e a própria relação sexual. Diante disso, essa forma de violência caracteriza-se por ser uma transposição de limites de direitos humanos, de papéis, de regras sociais e familiares (Centro de Referência, Estudos e Ações sobre Crianças e Adolescentes [CECRIA], 1997; Faleiros, 2000).

$\mathrm{O}$ abuso sexual pode ser tanto extrafamiliar como intrafamiliar. O extrafamiliar é quando incide fora do seio familiar, ou seja, o abusador é alguém com quem não se tem grau de parentesco algum (Libório, 2003). O intrafamiliar envolve relação sexual entre pessoas com grau próximo de parentesco sanguíneo ou por afinidade (Poli, 2001).

Segundo a gravidade do ato, os abusos sexuais podem ser divididos em: (a) abusos sensoriais: como pornografia, exibicionismo, linguagem sexualizada; (b) abusos por estimulação: como carícias impróprias em partes consideradas íntimas, masturbação, contatos genitais incompletos; e (c) abusos por realização: tentativa de violação ou penetração, oral, anal ou genital.

A exploração sexual comercial de crianças e adolescentes (ESCCA) configura-se como atividade através da qual adultos "tiram proveito" de crianças e adolescentes, em que há a presença de um comércio em torno dessa atividade, cujo pagamento pode ser financeiro ou de outra espécie. Abrange as modalidades turismo sexual (deslocamento de pessoas de suas regiões de origem com o objetivo de envolvimento sexual), tráfico e venda de pessoas (para propósitos sexuais) e pornografia infantil (representação, distribuição ou uso de material, exibição, através de quaisquer meios, de criança engajada em atividades sexuais) (End Children Prostitution, pornography and Trafficking for Sexual Purpose [ECPAT], 2006; Leal, 1999; Libório, 2003).

A Organização Internacional do Trabalho (OIT, 2005), na Convenção 182, situa a Exploração Sexual Comercial de Crianças e Adolescentes (ESCCA) como atividade de trabalho, considerando-a como uma das piores formas de trabalho infantil. Trata-se de atividade de trabalho, uma vez que se refere ao processo de se tirar proveito do trabalho sexual de outros forjando-se um mercado do sexo. Um comércio que consiste na venda da própria relação sexual e da imagem do corpo e de relações sexuais ao vivo, ou fotografada e filmada. A OIT (2005) denomina como piores formas as atividades de trabalho infantil que, por sua natureza ou pelas circunstâncias em que se desenvolvem, podem ser prejudiciais para a saúde e para o desenvolvimento moral de crianças e adolescentes.

A exploração sexual de crianças e adolescentes é fenômeno que tem suas raízes na estrutura social, nos aspectos culturais, psicossociais e jurídicos (Faleiros, 2000; Leal, 1999). A pobreza é considerada por diversos autores (CECRIA, 1997; Libório, 2003) um dos grandes viabilizadores da inserção de crianças e adolescentes no espaço da exploração sexual. Ora, tal contexto social implica dificuldades da família, que, na garantia das necessidades básicas dos seus membros, acaba transferindo às crianças e adolescentes, desde muito cedo, as exigências de trabalho e de subsistência. Cabe aqui salientar que a pobreza, isoladamente, não pode ser considerada a única causa da exploração sexual, mas ela é um importante fator de vulnerabilidade. A essa vulnerabilidade, associa-se a dimensão cultural, que envolve questões de gênero, etnia e raça.

No caso da discriminação de gênero, é uma causa arraigada da exploração sexual porque envolve relações desiguais, entre homem e mulher, carregadas de poder e de representações estereotipadas. O poder na família e na sociedade é basicamente concentrado no homem e mantido por esse; já as representações estereotipadas da mulher a fazem ser vista como objeto sexual, e o seu corpo, como mercadoria à disposição do homem; há divisões desiguais das responsabilidades familiares entre o feminino e o masculino (Libório, 2003; Saffioti, 1997).

A dimensão étnica encontra respaldo na literatura (Alberto, 2002; Leal, 1999; Libório, 2003; OIT, 2006) segundo a qual essa é uma herança decorrente do período escravista, quando negros eram coisificados e seu valor era instituído por sua capacidade para o trabalho e, também, para o ato sexual com fins de reprodução da mãode-obra. Com o fim da escravidão, a discriminação tem continuidade através de um processo de naturalização, estigmatização e exploração sexual das pessoas afrodescendentes.

Há, ainda, os fatores adicionais que conduzem, direta ou indiretamente, à ESCCA, como: corrupção, ausência de leis ou a existência de leis inadequadas, o descumprimento da lei e a limitada sensibilidade da pessoa encarregada da aplicação dessas leis sobre os efeitos nocivos nas crianças. Isso favorece a exploração sexual comercial pelas redes criminais, por indivíduos e famílias. É de se destacar, também, o adultocentrismo, ou seja, o poder que os adultos exercem sobre as crianças e adolescentes.

A ESCCA pode levar a graves consequências, inclusive à morte. Compromete o desenvolvimento físico, psicológico, espiritual, moral e social das crianças; favorece o aparecimento de gravidez precoce; mortalidade materna; lesões; atraso no desenvolvimento; incapacidade física; doenças sexualmente transmissíveis (Alberto, 2002; CECRIA, 1997; Faleiros, 2000; Libório, 2003).

O Brasil é reconhecido como país que viola direitos humanos, inclusive de crianças e adolescentes. Em estudo feito pelo Grupo de Pesquisa sobre Violência e Exploração Sexual (VIOLES), da Universidade de Brasília, entre 1996 e 2004, usando um conjunto de documentos, construiu-se a Matriz Intersetorial, uma ferramenta constituída de informações sistemáticas (quanti-qualitativas) com o objetivo de se analisar a situação da exploração sexual comercial de crianças e adolescentes. Os dados revelaram, entre outras coisas: há 930 municípios com 
exploração sexual comercial de crianças e adolescentes no Brasil, sendo que, na Paraíba, há 27 municípios, entre os quais, João Pessoa (VIOLES, 2006).

Mas, paradoxalmente, o Brasil também é reconhecido internacionalmente como um país especialmente "bem sucedido" na articulação entre governo e sociedade para fins da garantia dos direitos de crianças e adolescentes. A Constituição da República Federativa do Brasil de 1988 incorporou, em seu art. 227, a Doutrina Jurídica da Proteção Integral à Infância. Com isso, pela primeira vez na história do país, a criança passou a ser tratada como prioridade absoluta.

Embora seja considerado crime, o abuso sexual e a exploração sexual comercial não constam nos documentos de natureza jurídica. Em revisão desses documentos, Poli (2001) mostrou que a expressão "abuso sexual" consta em apenas um documento de natureza jurídica, no Estatuto da Criança e do Adolescente (ECA), art. 130. As expressões "prostituição" e "exploração sexual" aparecem também no ECA, no art. 244A, o qual determina que é crime "submeter a criança ou adolescente, como tais definidos no caput do art. $2^{\circ}$ desta lei, à prostituição ou à exploração sexual."

A legislação penal não contempla as expressões "abuso sexual" e "exploração sexual comercial". Os crimes de natureza sexual, e que dizem respeito a crianças e adolescentes, assim definidos na Lei penal - Código Penal são: Estupro, art. 213 (conjunção carnal mediante violência ou grave ameaça); Atentado violento ao pudor, art. 214 (ato libidinoso diverso de conjunção carnal); Atentado ao pudor mediante fraude, art. 216 (Induzir alguém, mediante fraude, a praticar ou submeter-se à prática de ato libidinoso diverso da conjunção carnal); art. 217; Sedução (Revogado); Corrupção de menores, art. 218 (corromper ou facilitar a corrupção de pessoa maior de 14 (catorze) e menor de 18 (dezoito) anos, com ela praticando ato de libidinagem, ou induzindo-a a praticá-lo ou presenciá-lo).

Percebe-se, pela leitura do dispositivo legal, que o objeto jurídico são os costumes. Trata-se, na realidade, da moral sexual. Os crimes sexuais foram ordenados na categoria costumes. Este último é o bem maior eleito acima da violência contra a pessoa. Logo são de ação privada os tipos de penas contidos no capítulo dos crimes contra os costumes. O ofendido ou representante legal é o "dono" da ação. São irrelevantes para a comunidade, atingem apenas a esfera privada da família ou do ofendido, cabendo a este decidir se devem ser punidos os abusadores, ou esquecer o ocorrido (Pinto, 1995).

A exceção é o caso da família pobre. No caso de o crime ser praticado com abuso do pátrio poder, a ação é pública incondicionada, ou seja, o crime é considerado contra a comunidade, e o dono da ação é o Estado (Pinto, 1995).

O ECA (2005), concebido como a doutrina da proteção integral, contém, além dos art. 130 e 244-A, acima referidos, o art. 240, que proíbe produções artísticas que utilizem criança ou adolescente em cena pornográfica, de sexo explícito ou vexatória; o art. 241, que determina ser crime divulgar ou publicar, por qualquer meio de comunicação, inclusive rede mundial de computadores ou internet, imagens com pornografia ou cenas de sexo explícito envolvendo criança ou adolescente; e o art. 245, que versa sobre a obrigatoriedade de médicos, professores ou responsáveis por estabelecimento de atenção à saúde, de ensino fundamental, pré-escola ou creche, comunicarem à autoridade competente os casos de que tenham conhecimento, envolvendo suspeita ou confirmação de maus tratos contra criança ou adolescente.

O ECA (2005) determina também a forma de atuação das entidades governamentais e não governamentais na defesa e na garantia dos direitos de crianças e adolescentes, assim como na política de atendimento dos direitos, o que, segundo o art. 86, se dará mediante um conjunto articulado de ações.

A complexidade do fenômeno da violência sexual e o fato de os agressores, vítimas e aliciadores muitas vezes encontrarem-se nas famílias e difundidos na sociedade, implicam que o enfrentamento da questão seja efetivado por muitos canais, articulado e organizado em redes. As redes partem da articulação de atores, organizações e forças existentes no território, para uma ação conjunta multidimensional, com responsabilidade partilhada (parceria) e negociada, em que a perspectiva da totalidade predomina sobre a fragmentação, e onde cada parte potencializa recursos que, juntos, se tornarão mais eficientes (Faleiros, 2000).

A partir da década de 90, em decorrência de assassinatos de crianças em situação de rua, violência contra a mulher e exploração sexual comercial de crianças e adolescentes, que tiveram espaço no cenário brasileiro (Leal, 2001), surgiram no país vários grupos e organizações não governamentais que passaram a lidar com a questão, a canalizar denúncias e a pressionar para que houvesse um efetivo enfrentamento do problema. Foram realizadas CPIs para investigação do problema em nível local, a exemplo do Distrito Federal e da Paraíba, e das cidades de Goiânia e Fortaleza. A sociedade civil, como parte da estratégia para fazer com que o tema estivesse presente na agenda prioritária do País, manteve-se articulada, realizando freqüentes campanhas e eventos, tanto regionais como nacionais, para debater e enfrentar o problema da exploração sexual. Nesse contexto, insere-se o enfrentamento da violência sexual, cujas bases se assentam historicamente em duas frentes, nacional e internacional, e que se articulam (Comissão Parlamentar Mista de Inquérito [CPMI], 2004).

A base internacional de toda a legislação específica tem como referência os seguintes documentos: Declaração sobre os Direitos da Criança, ratificada em 26/9/1923 em Genebra; Declaração Universal dos Direitos Humanos, promulgada pela ONU em 1948; segunda Declaração Universal dos Direitos da Criança, aprovada em 1959; Convenção sobre os Direitos da Criança, de 1989; De- 
Alberto, M. F. P., Silva, A. C. S., Gomes, V. C., Santana, R. V. M. \& Soares, A. M. (2012). Os Agentes Sociais da Rede de Proteção e Atendimento no Enfrentamento da Exploração Sexual Comercial.

claração de Viena de 1993; o I Congresso Mundial contra a Exploração Sexual Comercial de Crianças e Adolescentes, realizado em Estocolmo-Suécia em 1996; o II Congresso Mundial contra a Exploração Sexual Comercial de Crianças e Adolescentes, realizado em Yokohama em 2001 e o III Congresso Mundial contra a Exploração Sexual Comercial de Crianças e Adolescentes, realizado no Brasil em 2008.

Os três Congressos se constituíram em marco da mobilização global contra a exploração sexual comercial de crianças. Uma das maiores contribuições desses congressos foi a adoção do termo exploração e violência sexual contra crianças e adolescentes, e não o termo prostituição infantil, passando a entender que a exploração sexual comercial (ESC) é um fato que interfere na vida de uma criança ou de um adolescente, anulando seus direitos mais elementares, fundamentais para um desenvolvimento biopsicossocial saudável (Alberto, 2002; CECRIA, 1997; Faleiros, 2000; Bontempo, Bosetti, César, \& Leal, 1995; Libório, 2003).

As bases nacionais para o enfrentamento da violência sexual de crianças e adolescentes tem os seguintes marcos principais: (a) O movimento Pró-Constituinte e a Promulgação da Constituição Federal de 1988, cunhada de Constituição cidadã, em cujo seio contempla o art. 227, que versa sobre a criança e o adolescente como sujeitos de direitos. (b) A aprovação do ECA, em 1990, com ampla articulação de diferentes atores da sociedade civil. (c) A Comissão Parlamentar de Inquérito (CPI) da Prostituição Infantil da Câmara, em 1993, que deu maior visibilidade à questão no país. (d) A aprovação do Plano Nacional de Enfrentamento da Violência Sexual Infanto-Juvenil, no ano 2000 (Ministério da Justiça, 2001), com ampla participação de governo e da sociedade. O plano abriu caminho para a inclusão, no Plano Plurianual (PPA/2000-2003), de um programa específico, o Sentinela. (e) O compromisso pela erradicação da violência sexual, expresso no Pacto pela Paz, a partir da realização, em 2001, da IV Conferência Nacional dos Direitos das Crianças e dos Adolescentes, que ratifica a implantação do Plano Nacional de Enfrentamento à Violência Sexual Infanto-Juvenil. (f) A conclusão, em 2002, da Pesquisa sobre Tráfico de Mulheres, Crianças e Adolescentes para Fins de Exploração Sexual Comercial no Brasil (PESTRAF). A maior parte dos programas surgidos posteriormente usa como base de trabalho as informações levantadas pela PESTRAF. (g) A constituição, em 2002, do Comitê Nacional de Enfrentamento ao Abuso e Exploração Sexual, uma rede de entidades não governamentais e representantes de setores do Executivo e da cooperação internacional. O comitê seria o espaço para o debate e monitoramento de programas e políticas públicas nessa área, fomentando ainda a mobilização regional e juvenil. (h) Outro marco promissor seria a Comissão Parlamentar Mista de Inquérito - CPMI do Congresso Nacional, instalada em 2003 e concluída em 2004, reunindo Deputados e Senadores, e que investigou as situações de violência e redes de exploração sexual de crianças e adolescentes no Brasil. A referida CPMI propôs, inclusive, mudanças na Legislação Brasileira, com vistas inclusive a incluir a violência sexual como crime contra a pessoa.

Para efetivar a idéia de que as políticas sociais são imprescindíveis para assegurar a proteção integral, a descentralização, a participação da sociedade civil e efetivar a articulação, a Constituição Federal de 1988 e o Estatuto da Criança e do Adolescente (1990) criaram um Sistema de Garantias de Direitos que se apóia em três eixos: promoção de direitos, defesa e controle social. A Promoção visa à realização do Direito. Fazem parte do eixo: setores públicos (gestores da saúde, educação, assistência social), Conselhos de Direitos da Criança e do Adolescente e Conselhos Setoriais (Assistência Social e Educação). A defesa visa à responsabilização no caso de omissão, falta ou oferta irregular dos Direitos por parte da família, do Estado ou da sociedade. Fazem parte do eixo: Ministério Público, Ministério do Trabalho, Conselho Tutelar, Judiciário, Defensoria Pública, Centros de Defesa de Direitos Humanos. O controle social visa ao acompanhamento e fiscalização do cumprimento dos Direitos. Fazem parte do eixo: entidades da sociedade civil, articuladas ou não (Cabral, 1999).

O Plano Nacional de Enfrentamento da Violência Sexual Infanto-Juvenil (Ministério da Justiça, 2001) também constitui-se um documento que se estrutura em torno de eixos. Compõe-se de seis eixos estratégicos, sendo definidos em cada um deles os objetivos e metas a serem alcançados, as ações a serem executadas, os prazos e as parcerias. É importante ressaltar que o Plano é orgânico e integrado, o que significa que sua operacionalização implica, obrigatoriamente, ações articuladas dos diferentes eixos. São eles: Análise da Situação, Mobilização e Articulação, Defesa e Responsabilização, Atendimento, Prevenção, Protagonismo Infanto-Juvenil.

Para o monitoramento e a avaliação do Plano Nacional, foi sugerida a criação do Fórum Nacional pelo Fim da Violência Sexual de Crianças e Adolescentes, com o objetivo de reunir organizações do Governo e da Sociedade Civil para o acompanhamento da implantação e implementação das ações do Plano Nacional. O CONANDA e os Conselhos de Direitos Estaduais e Municipais são as instâncias de deliberação, controle e acompanhamento do Plano Nacional.

\section{Método}

\section{Participantes}

Participaram desta pesquisa 31 Agentes Sociais de 12 entidades. Os Agentes Sociais são pessoas que trabalham nas entidades que compõem a Rede de Proteção a crianças e adolescentes no município de João Pessoa. Essa rede é composta por Organizações Governamentais, Organizações Não Governamentais, Sistema de Justiça, Controle Social, Instâncias de Direito, confor- 
me preconiza o Plano Nacional de Enfrentamento da Violência Sexual contra Crianças e Adolescentes.

\section{Instrumentos}

Utilizou-se um questionário com questões abertas e fechadas. $\mathrm{O}$ referido instrumento pretendeu contemplar as vantagens das questões abertas e das questões fechadas. No caso das questões abertas que não forçam o respondente a enquadrar-se em questões preestabelecidas e no caso da questões fechadas, além de autorrespondentes, situa-se de modo objetivo o conhecimento de determinados fatos. Desse modo, com o formato do referido instrumento pretendeu-se abordar o conhecimento, a percepção, as crenças, as atitudes e os comportamentos dos referidos agentes sociais sobre a exploração sexual comercial de crianças e adolescentes. O questionário versava sobre: Dados das entidades; Dados socioescolares dos Atores Sociais; Conhecimento do Sistema de Proteção; Conhecimento sobre Legislação Nacional e Internacional; Percepção da ESCCA; Formas de Enfrentamento da ESCCA; Procedimentos e Medidas em casos de suspei-tas, identificações, denúncias e notificações da ESCCA. O instrumento utilizado baseou-se em instrumento elaborado pela Organização Internacional do Trabalho (OIT) para se fazer a Avaliação das Piores Formas de Trabalho Infantil (2004).

\section{Procedimentos}

Buscaram-se, inicialmente, a orientação e informações do Centro de Referência Especializado da Assistência Social (CREAS), anteriormente nominado como Programa Sentinela, especializado no atendimento psicossocial a crianças e adolescentes vitimizados pela violência, assim como a suas famílias. Iniciou-se o contato com as entidades para apresentação dos objetivos da pesquisa e obtenção de autorização por parte delas das informações. Os participantes foram contatados e convidados a participar da pesquisa. Agendava-se um horário e, mediante assinatura do Termo de Consentimento, conforme a Resolução 196 do Conselho Nacional de Saúde, que versa sobre a Ética na pesquisa, procedia-se à aplicação dos questionários. Os instrumentos eram autoaplicáveis. Os pesquisadores permaneciam junto aos participantes apenas para esclarecer eventuais dúvidas.

Inicialmente, estava estabelecida como critério a identificação de todas as instituições que compõem a Rede de proteção, e a aplicação de dois questionários por instituição identificada, um com a direção e outro com um técnico. Devido, porém, às dificuldades de acesso e disponibilidade de tempo dos Atores, não foi possível alcançar a meta em todas as 15 entidades identificadas, inicialmente, como Rede de enfrentamento da violência sexual no município de João Pessoa. No total, foram realizadas 31 entrevistas, em 12 instituições, sendo que 8 foram invalidadas porque não foram respondidas todas as questões, restando 23 entrevistas consideradas válidas.
Após a aplicação, os dados foram categorizados utilizando-se a análise de conteúdo temático nos moldes propostos por Bardin (1977). Procedeu-se à tabulação com a finalidade de se fazer o recorte das unidades temáticas; a codificação, com a finalidade de se agrupar o recorte das unidades temáticas, para a construção das categorias; a categorização, com a finalidade de se elaborar uma representação simplificada do conteúdo; e, por fim, a inferência e a interpretação, com as respectivas finalidades de se descrever os dados e se estabelecer relações a partir da revisão da literatura sobre o tema, adotada neste trabalho.

\section{Resultados}

A análise de conteúdo temático possibilitou a organização e apresentação dos seguintes aspectos: dados institucionais, contexto e perfil dos Agentes sociais, conhecimento sobre o sistema de proteção, percepção da ESCCA, perspectivas dos Agentes sociais sobre o enfrentamento da exploração sexual comercial de crianças e adolescentes.

\section{Contexto e Perfil}

As entidades responsáveis pelo enfrentamento da violência sexual de crianças e adolescentes na cidade de João Pessoa, nas quais atuam os Agentes Sociais que participaram desta pesquisa, compõem quatro categorias: Organizações Governamentais, Organizações Não Governamentais, Sistema de Justiça e Instâncias de Direitos.

Dos 23 participantes cujos questionários foram considerados válidos, 18 são do sexo feminino e cinco, do sexo masculino. Esses dados possibilitam a compreensão da dimensão de gênero, ou seja, essa atividade de trabalho ligada à proteção ainda é uma dimensão considerada feminina, pois se assemelha à continuidade do papel social da mulher na sociedade, de atenção e cuidado da família. Percebeu-se entre os participantes uma predominância de técnicos, o que é compreensível, considerando-se a operacionalização das atividades, que requisitam principalmente as funções de assistentes sociais e psicólogos.

\section{Conhecimento sobre o Sistema de Proteção}

Ao serem indagados se, no Brasil, é possível se pedir proteção para crianças e adolescentes e suas famílias vítimas de violência intrafamiliar, dos 23 participantes, 21 responderam que sim, um respondeu que não, e um não respondeu.

Os lugares apontados pelos participantes para se solicitar medidas de proteção em caso de violência sexual intrafamiliar foram: Conselhos Tutelares, Ministério Público, Juizado da Infância e Juventude, Delegacia da Infância e Juventude, Polícia Federal, Organizações Não Governamentais (ONG), Programa Sentinela, Abrigos, Centro de Referência para Crianças e Adolescentes em 
Situação de Violência, Fórum de Defesa dos Direitos da Criança e do Adolescente.

Para se verificar o conhecimento dos participantes sobre legislações protetivas, indagou-se o Brasil havia ratificado convenções, tratados, protocolos internacionais relacionados à proteção dos direitos das crianças e adolescentes em situação de ESCCA. Dos entrevistados, 17 responderam que sim, três não souberam, e três não responderam. Ainda de acordo com essa concepção, indagou-se também se seria possível implementar-se, na prática, leis que punam a exploração sexual de crianças e adolescentes, 20 participantes responderam que sim, Um participante respondeu negativamente, um respondeu que não sabia, e um não respondeu.

Questionados se seria possível se processar um estrangeiro após ele ter deixado o país, depois de fazer turismo sexual com criança e adolescente, 11 pessoas disseram que sim, dois disseram que não, seis não souberam responder, e quatro não responderam. Percebe-se, pois, a partir da análise dos dados, que apenas 11 dos participantes da pesquisa conseguiram identificar corretamente a questão, enquanto 12 pessoas desconhecem a legislação no que diz respeito a essa questão.

\section{Percepção da ESCCA}

Para se identificar a percepção que os operadores têm acerca da ESCCA, abordou-se o assunto a partir de três questões: (a) aspectos negativos e positivos da ESCCA; (b) a forma de como se efetivar a proteção; (c) contribuição das crianças e adolescentes para o enfrentamento da ESCCA. A maioria dos entrevistados respondeu não haver resultados positivos. Entretanto houve quem identificasse como resultado positivo o fato de se atender às necessidades materiais dos sujeitos em situação de exploração; entre essas necessidades, apontou-se: "matar a fome e ter abrigo".

Os resultados negativos identificados foram: violências físicas, psicológicas e estruturais; a vulnerabilidade da exposição a riscos de: morte, contaminação por doenças sexualmente transmissíveis, gravidez precoce e uso de drogas; baixa autoestima, e possibilidade de perda da identidade; exclusão social, com violação dos direitos previstos no ECA; baixa escolaridade; perda de confiança nos adultos e das perspectivas de futuro; depressão e suicídio.

Sobre a prevenção da ESCCA, responderam que se poderia: implementar políticas públicas; medidas educacionais; articular instituições; resolver a questão social; melhorar a renda; acabar a pobreza; fazer mais denúncias para torná-la visível; investir na família; criar leis mais rígidas; preparar melhor os conselheiros tutelares e divulgar o ECA nas escolas. Dentre as entidades apontadas com o papel de prevenir a ESCCA, destacam-se dois grupos: (a) os que nomeiam genericamente Estado, Família e Sociedade; (b) os que nomeiam especificamente: Conselhos Tutelares, Juizado, Rede de Defesa da Criança e do Adolescente e a Escola.
Quanto à contribuição de crianças e adolescentes no enfrentamento, as respostas dadas possibilitam a compreensão de que as respostas dos participantes revelam uma forma de se perceber a criança e o adolescente. As respostas enquadram-se em quatro grupos: (a) são incapazes de contribuir porque são vulneráveis, (b) culpabilizam as crianças e adolescentes ao responderem que eles deveriam evitar, (c) estando inseridos em políticas sociais e básicas e em políticas de proteção especial, (d) denunciando e sendo informados dos riscos.

\section{Perspectivas dos Atores Sociais em Relação ao Enfrentamento da ESCCA}

Indagados se a entidade na qual trabalham tem a obrigação de participar do enfrentamento da ESCCA, dos 23 participantes cujos questionários foram considerados válidos, 21 pessoas responderam que sim e duas pessoas responderam que não.

O modo como os profissionais que trabalham nessas instituições compreendem a participação delas no enfrentamento da ESCCA é representado por denúncia, fiscalização, investigação, punição, encaminhamento e notificação. Há que se destacar a forma como a notificação e a denúncia foram representadas nas falas. A notificação aparece como uma atividade que aciona outras instituições ou como é comunicada a outras instituições ou autoridades. Já a denuncia é retratada nas falas dos atores sociais com um caráter de registro policial e de divulgação na mídia, e, quando denunciam, parecem deixar de ter responsabilidade, passando-a a outrem.

Questionados quais seriam os órgãos ou instituições responsáveis por receberem denúncias de ESCCA, os entrevistados identificaram: Conselhos Tutelares, Ministério Público, Justiça, Polícia, ONGs, Programas, Gestor de Políticas e Instâncias de Representação.

Alguns participantes da pesquisa conhecem ou identificam que pode ser feita a denúncia, mas nem todos sabem necessariamente onde fazê-la. Isso é complicado, porque o fato de serem profissionais ligados às instituições de proteção pode dificultar a garantia de alguns direitos, a investigação e punição dos envolvidos, além de protelar a cultura da impunidade, que, no caso específico da ESCCA, naturaliza a violência sexual contra crianças e adolescentes.

Ao serem indagados se sua instituição tem alguma norma ou procedimento específico para agir, no caso de se suspeitar que uma criança ou adolescente estejam em situação de ESC, 20 pessoas responderam que sim e três pessoas responderam que não. As respostas das pessoas entrevistadas permitem, de modo geral, vislumbrar que, para elas, as Organizações Governamentais (OG) atendem, notificam, encaminham; enquanto as ONGs atendem, encaminham e denunciam. Já as instâncias de direitos protegem, averiguam, denunciam e notificam. O Sistema de Justiça fiscaliza, investiga, denuncia, abre inquéritos e pune. 
Questionados se a instituição na qual trabalham adota procedimentos específicos para notificação de ESCCA, 16 pessoas disseram que sim, cinco pessoas disseram que não e duas disseram não saber. Os procedimentos específicos são os mesmos determinados no ECA como pertinentes às instituições que compõem a política de atendimento dos direitos da criança e do adolescente.

Indagados sobre as medidas de acompanhamento tomadas, ao se identificar uma criança ou adolescente vítimas de Exploração Sexual Comercial, as respostas obtidas foram: visitas domiciliares por assistentes sociais e psicólogos; encaminhamentos para as instituições denominadas pelos participantes como de atendimento (Delegacia, Sentinela, Ministério Público, Conselho Tutelar, Secretaria de Saúde e Programas de Políticas Assistenciais, Bolsa Família e Programa de Erradicação do Trabalho Infantil [PETI]); verificação in loco.

A medida mais citada pelos Agentes Sociais, ao se identificar uma criança ou adolescente vítimas de ESC, foi o encaminhamento para o Conselho Tutelar e para o CREAS. Reconhece-se, portanto, a importância desses dois serviços. Apesar de, novamente, o tipo de resposta dada possibilitar a inferência de, em aparência, alguns identificarem que algo deva ser feito, mas não se sabe como proceder. Eis um exemplo desse tipo de resposta: "encaminhar para os órgãos competentes". Houve ainda algumas respostas que culpabilizavam as vítimas, por exemplo: "as medidas de acompanhamento seriam medidas educativas para que elas evitassem" e "devolução das crianças aos pais".

As respostas obtidas foram: medidas educacionais, medidas sociais, atendimento psicológico com a criança e/ ou a família, desenvolver atividades culturais, e, também, trabalhar os possíveis aliciadores. Outra medida tomada para mudar os fatores que afastaram as crianças e adolescentes do lar, citada pela maioria dos atores sociais, foi o envio para o atendimento psicológico.

\section{Discussão}

No que diz respeito ao conhecimento sobre a Legislação pertinente ao enfrentamento da ESCCA, a maioria dos atores sociais revelou que tem conhecimento sobre o Sistema de Proteção e a Lei de Defesa dos Direitos da Criança e do Adolescente - conhecem o direito de ser protegido. Entretanto os dados revelam que nem todos os participantes dominam a legislação pertinente ao Código Penal quanto à punição dos abusadores e à extensão dos direitos de proteção à família.

Percebe-se que, de modo geral, todos identificam um conjunto de instituições a que podem solicitar medidas de proteção, em caso de violência sexual intrafamiliar, mas nem todos têm clareza do tipo de medida a ser buscada em cada uma. Sabem que as crianças e adolescentes têm direitos, mas nem todos sabem o que compete a cada instituição responsável pela Defesa, Proteção e Garantia dos Direitos de crianças e adolescentes, componente da rede de serviço e atendimento e que são responsáveis pelo enfrentamento da violência sexual infanto-juvenil. Um exemplo disso, o CREAS, que não pode oferecer proteção em caso de violência sexual contra a criança ou adolescente. Essa proteção tem que ser pedida ao Ministério Público. Nem mesmo o Conselho Tutelar pode dar tal proteção, a não ser, provisoriamente, enquanto encaminha o caso ao Ministério Público.

A literatura sobre o tema revela que a Constituição Federal, no art. 227, o Estatuto da Criança e do Adolescente (art. 101, inciso IV), a Lei Orgânica da Assistência Social (LOAS) nos art. $2^{\circ}, 22$, parágrafo $2^{\circ}$, art. 23, parágrafo único, incisos I e II, determinam que cabem ao Estado, nas esferas federal, estadual e municipal, medidas específicas de proteção a crianças, a adolescentes e a suas famílias em caso de ameaça ou violação de direitos. Ainda mais, o art. 101 do ECA (2005) determina que cabe à autoridade competente determinar as medidas de proteção. Por autoridade competente, o ECA (2005) define, no art. 146, que é o Juiz da Infância e Adolescência. Embora a maioria dos atores sociais tenha conhecimento sobre essas medidas de proteção, houve participantes que não detinham conhecimento acerca das medidas de proteção para crianças, adolescentes e famílias vítimas de violência sexual, assim como vários atores sociais responderam que solicitariam medidas de proteção junto ao Conselho Tutelar e ao Programa Sentinela.

Em relação ao posicionamento do Brasil diante da agenda internacional, vale ressaltar que o país é signatário dos principais atos relativos ao tema, destacando-se a Declaração sobre os Direitos da Criança (1923), a Declaração Universal dos Direitos Humanos (1948), a Segunda Declaração Universal dos Direitos da Criança (1959), a Convenção sobre os Direitos da Criança (1989), a Declaração de Viena (1993). No caso da Legislação Internacional relacionados à proteção dos direitos das crianças e adolescentes em situação de ESCCA, o Brasil é signatário de vários tratados e convenções internacionais, entre os quais, a Convenção 182 das piores formas de trabalho; entretanto a maioria dos participantes desconhece as Leis Internacionais e a situação do Brasil em relação a elas.

Baseado em revisão da literatura sobre o enfrentamento da ESCCA (Alberto 2002; CECRIA, 1997; Faleiros, 2000; Libório, 2003), constata-se que os profissionais que atuam nessas instituições, responsáveis pelo enfrentamento da ESCCA e pela operacionalização do sistema de garantias, têm uma percepção dúbia sobre a ESCCA, variando entre certo conhecimento das conseqüências para as crianças e adolescentes vitimizados e uma leve referência à existência de aspectos positivos.

Ao situarem a contribuição das crianças e adolescentes no enfrentamento, a percepção também varia: para uns, esses cidadãos em processo de desenvolvimento são incapazes de contribuir no enfrentamento (devem ser pro- 
tegidos); para outros participantes, são eles culpados pela violência de que são vítimas; e, para outros, podem ser protagonistas (devem denunciar).

Inferimos que a percepção dos atores sociais que participaram desta pesquisa oscila entre a concepção das crianças e adolescentes vitimizados, como sujeitos que devem ser protegidos, e a responsabilidade (ou obrigatoriedade) do Estado de fazê-lo. Mas não está muito nítido, nas falas desses atores, a visão de direitos humanos que estão positivados, que não precisam de regras para serem reconhecidos independentemente de lei. Talvez o tipo de percepção desses atores seja um misto daqueles aspectos apontados como naturalizadores da violência sexual contra crianças e adolescentes, com raízes na estrutura social, nos aspectos culturais, psicossociais, jurídicos, dimensões históricas, de raça, gênero, idade, impunidade, limitada sensibilidade da pessoa encarregada da aplicação dessas leis sobre os efeitos nocivos da ESCCA (Alberto, 2002; CECRIA, 1997; Faleiros, 2000; Leal, 1999; Libório, 2003; Saffioti, 1997).

A participação no enfrentamento da ESCCA, preconizada quer no ECA, quer no Plano Nacional de Enfrentamento da ESCCA, deve ocorrer por um conjunto de ações de denúncias, procedimentos em casos de suspeitas, notificação, medidas de acompanhamento ao se identificar e medidas tomadas para mudar os fatores que afastam crianças e adolescentes do lar. Esse conjunto de ações deve ser viabilizado através da articulação das entidades (Alberto, 2002; CECRIA, 1997; Faleiros, 2000; Leal, 1999; Libório, 2003; Saffioti, 1997).

A análise dos dados possibilita a compreensão de que todos conhecem ou identificam que pode ser feita a denúncia, mas nem todos os participantes revelaram, na pesquisa, onde fazê-la. Percebem cada grupo com funções específicas em caso de suspeita: $\mathrm{OG}$ e $\mathrm{ONG}$ atendem e encaminham; Instância de Direito averigua, notifica, protege e Sistema de Justiça, fiscaliza, investiga e pune. Mas não revelaram, nesta pesquisa, clareza do papel que a instituição à qual cada um está vinculado deve desempenhar no enfrentamento, pois algumas têm obrigatoriedade de fazer notificação, tais como OG de saúde, e educação e instância de direito, mas alguns dos Atores Sociais não revelaram ter clareza disso. Assim como também falta clareza na forma como pode se dar atuação articulada, em rede.

As medidas de acompanhamento tomadas ao se identificar uma criança ou adolescente vítimas de ESCCA são visitas domiciliares, encaminhamento e visitas in loco (Alberto, 2002; CECRIA, 1997; Faleiros, 2000; Leal, 1999; Libório, 2003; Saffioti, 1997). Além de verificada a hipótese de maus-tratos, opressão ou abuso sexual impostos pelos pais ou responsável, a autoridade judiciária poderá determinar, como medida cautelar, o afastamento do agressor da moradia comum (ECA, 2005, art. 130). Os dados revelam que, o mais das vezes, a visita domiciliar até ocorre, mas depois dos enca- minhamentos o processo não prossegue, pois não há o acompanhamento dos encaminhamentos.

Percebe-se, a partir dos dados, que, para os participantes desta pesquisa, a concepção de atendimento é ampla, uma vez que as entidades elencadas para tal, embora possam desempenhar funções semelhantes, no Sistema de Garantias e no Plano Nacional de Enfrentamento da Violência Sexual contra crianças e Adolescentes, são concebidas como tendo funções específicas, porém complementares.

Nas medidas tomadas para se mudar os fatores que afastaram as crianças e adolescentes do seu lar, os Atores revelaram que faltam referências às ações de retaguarda e, principalmente, de justiça (de criminalização) dos abusadores. As respostas a medidas educacionais, medidas sociais e desenvolver atividades culturais são respostas reveladoras de que, na atuação com a criança ou o adolescente, prepondera $\mathrm{o}$ atendimento restrito, em sua maior parte, a intervenções centralizadas na vítima, e que em alguns momentos a culpabilizam. Faltam referências por parte dos atores sociais às ações da justiça, tanto no caso da criminalização e punição dos abusadores, quanto no das ações de retaguarda.

\section{Considerações Finais}

Baseada na análise das respostas dos atores sociais, com relação à temática trabalhada, a pesquisa possibilita a compreensão de que a maioria dos integrantes da rede de serviços e atendimentos responsáveis pelo enfrentamento da violência sexual infanto-juvenil possui conhecimento do papel da instituição na qual atuam, principalmente, tomando-se como referencial o Plano Nacional de Enfrentamento à Violência Sexual contra Crianças e Adolescentes, que traça a política de proteção integral para crianças e adolescentes em situação de exploração sexual comercial.

Todavia os dados possibilitaram a compreensão de que, embora a maioria dos atores sociais conheça teoricamente o papel das instituições em que trabalha, parcela significativa desses atores desconhece parte da Legislação (Punição, criminalização) que trata da problemática e desconhece as formas de se efetivar na prática o papel daquelas. Alguns não têm clareza sobre a prevenção e até culpabilizam às vítimas. Alguns também não têm clareza das medidas de proteção, nem clareza de como processá-las. A notificação, instrumento importante, inclusive determinado em Lei, não é adotado por todos e restringe-se, para alguns, a um jogo de empurra-empurra. Alguns também não têm clareza do papel de todas as instituições e do papel de cada uma no enfrentamento, assim como desconhecem como pode se efetivar a articulação interinstitucional. 


\section{Referências}

Alberto, M. F. P. (2002). A dimensão subjetiva do trabalho precoce de meninos e meninas em condição de rua em João Pessoa (PB). (Tese de Doutorado não-publicada). Programa de Pós-Graduação em Sociologia, Universidade Federal de Pernambuco, Recife, PE.

Bardin, L. (1977). Análise do conteúdo. Lisboa, Portugal: Edições 70.

Bontempo, D., Bosetti, E., César, M. A., \& Leal, M. L. P. (Eds.). (1995). Exploração sexual de meninas e adolescentes no Brasil. Brasília, DF: Organização das Nações Unidas para Educação, Ciência e Cultura.

Cabral, E. A. (Ed.). (1999). Sistema de garantia de direitos: Um caminho para a promoção integral. Recife, PE: Centro Dom Helder Câmara de Estudos e Ação Social.

Centro de Referência, Estudos e Ações sobre Crianças e Adolescentes. (1997). Fundamentos e politicas contra a exploração e abuso sexual de crianças e adolescentes: Relatório de estudo. Brasília, DF: Ministério da Justiça.

Comissão Parlamentar Mista de Inquérito. (2004). Com a finalidade investigar as situações de violência e redes de exploração sexual de crianças e adolescentes no Brasil: Relatório final. Brasília, DF: Autor.

Constituição da República Federativa do Brasil. (1988). Art. $227^{\circ}$. Brasília, DF: Presidência da República.

End Children Prostitution, Pornography and Trafficking for Sexual Purpose. (2006). Commercial sexual exploitation of children. Retrieved May 12, 2008, from http://ecpat.net/eng/ CSEC/faq/faq1.asp

Estatuto da Criança e do Adolescente. (1990). Lei 8.069. Brasília, DF: Ministério da Educação.

Faleiros, E. T. S. (2000). Repensando os conceitos de violência, abuso e exploração sexual de crianças e adolescentes. Brasília, DF: Thesaurus.

Leal, M. L. P. (1999). A exploração sexual comercial de meninos, meninas e adolescentes na América Latina e CaribeRelatório final-Brasil. Brasília, DF: Centro de Referência, Estudos e Ações sobre Crianças e Adolescentes.

Leal, M. L. P. (2001). A mobilização das ONGs para o enfrentamento da exploração sexual comercial de crianças e adolescentes no Brasil. (Tese de Doutorado não-publicada). Programa de Pós-Graduação em Serviço Social, Pontifícia Universidade Católica de São Paulo, SP.

Libório, R. M. C. (2003). Desvendando vozes silenciadas: As adolescentes em situação de exploração sexual comercial. (Tese de Doutorado não-publicada). Programa de Pós-Graduação em Psicologia, Universidade de São Paulo, SP.

Ministério da Justiça. (2001). Plano nacional de enfrentamento da violencia sexual infanto-juvenil. Brasília, DF: Autor.

Pinto, L. L. (1995). Painel Nacional sobre a exploração sexual de meninas e adolescentes no Brasil. In D. Bontempo, E. Bosetti, M. A. César, \& M. L. P. Leal (Eds.), Exploração sexual de meninas e adolescentes no Brasil (pp. 35-40). Brasília, DF: Organização das Nações Unidas para Educação, Ciência e Cultura.

Poli, M. E. H. (2001). Abuso sexual. Feminina, 29(7), 475477.

Organização Internacional do Trabalho. (2004). Boas práticas: Integração de gênero nas ações contra o trabalho infantil. Genebra, Suíça: Autor.
Organização Internacional do Trabalho. (2005). Convenio $n^{o}$ 182. Retrieved November 02, 2005 from http://www.ilo.org/ ilolex/spanish/convdisp2.htm

Organização Internacional do Trabalho. (2006). Relatório de pesquisa sobre as piores formas do trabalho infantil. In Organização Internacional do Trabalho, $A$ exploração sexual comercial de crianças e adolescentes. Brasília, DF: Autor.

Saffioti, H. I. B. (1997). No fio da navalha: Violência contra crianças e adolescentes no Brasil Atual. In F. R. Madeira (Ed.), Quem mandou nascer mulher? (pp. 134-211). São Paulo, SP: Rosa dos Tempos.

VIOLES - Grupo de Pesquisa sobre Tráfico de Pessoas, Violência e Exploração Sexual de Mulheres, Crianças e Adolescentes. (2006). Estudo analítico do enfrentamento da exploração sexual comercial de crianças e adolescentes no Brasil (1996-2004). Rio de Janeiro, RJ: Autor.
Recebido: 07/08/2009 $1^{a}$ revisão: $22 / 06 / 2010$ $2^{a}$ revisão: $20 / 10 / 2010$ Aceite final: 20/10/2010 